Eastern Illinois University

The Keep

Masters Theses

Student Theses \& Publications

$1-1-1994$

\title{
Perceived Influence Of Significant Others On Body Shape Of Female And Male College Students
}

Susan Kay Drake

Eastern Illinois University

This research is a product of the graduate program in Home Economics at Eastern Illinois University. Find out more about the program.

\section{Recommended Citation}

Drake, Susan Kay, "Perceived Influence Of Significant Others On Body Shape Of Female And Male College Students" (1994). Masters Theses. 456.

http://thekeep.eiu.edu/theses/456

This Thesis is brought to you for free and open access by the Student Theses \& Publications at The Keep. It has been accepted for inclusion in Masters Theses by an authorized administrator of The Keep. For more information, please contact tabruns@eiu.edu. 
PERCEIVED INFLUENCE OF SIGNIFICANT OTHERS ON BODY SHAPE OF FEMALE AND MALE COLLEGE STUDENTS

DRAKE 
TO: Graduate Degree Candidates who have written formal theses.

SUBJECT: Permission to reproduce theses.

The University Library is receiving a number of requests from other institutions asking permission to reproduce dissertations for inclusion in their library holdings. Although no copyright laws a re involved, we feel that professional courtesy demands that permission be obtained from the author before we allow theses to be copied.

Please sign one of the following statements:

Booth Library of Eastern Illinois University has my permission to lend my thesis to a reputable college or university for the purpose of copying it for inclusion in that institution's library or research holdings.

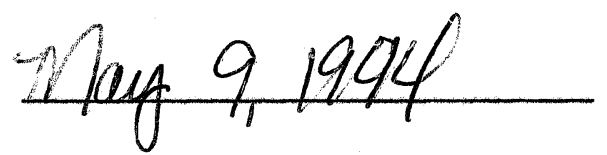

Date

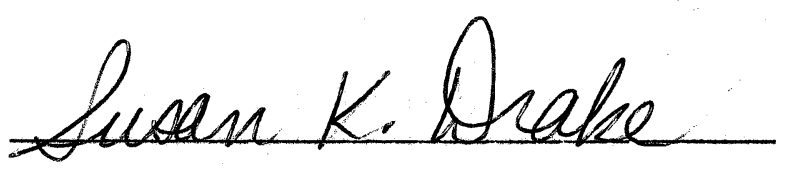

Author

I respectfully request Booth Library of Eastern Illinois University not allow my thesis be reproduced because

Date

Author

$\mathrm{m}$ 


Perceived Influence of Significant Others on Body
Shape of Female and Male College Students
(TITLE)

$B Y^{\prime}$

Susan Kay Drake

THESIS

SUBMITTED IN PARTIAL FULFILLMENT OF THE REQUIREMENTS

FOR THE DEGREE OF

Home Economics - Dietetics

IN THE GRADUATE SCHOOL, EASTERN ILLINOIS UNIVERSITY

CHARLESTON, ILLINOIS

1994

YEAR

I HEREBY RECOMMEND THIS THESIS BE ACCEPTED AS FULFILLING

THIS PART OF THE GRADUATE DEGREE CITED ABOVE
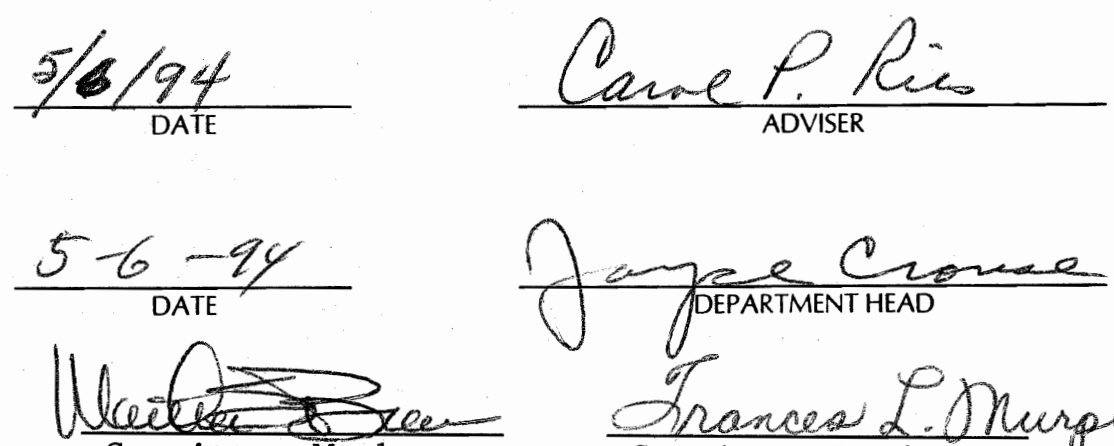

Committee Member

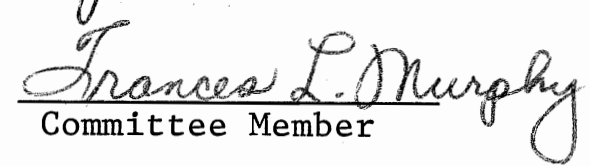


that most males and females felt little pressure from these sources to gain or lose weight, especially in comparison to perceived self-influence of males to gain (2.0) and of females to lose (3.1) weight. Females perceived their body size to be larger $(3.95, \mathrm{p}<.00)$ than how they believed their mother or sister (3.70), male friends (3.66), father (3.62) or boyfriend (3.53) viewed them. Males' perception of their current shape was consistent with their perceptions of how others viewed them. These results support prior research indicating that females are less satisfied than males with their body shape and that they feel pressure to be thin. While mean influence scores suggest little perceived pressure from significant others to gain or lose weight for the sample as a whole, perceived pressure from these sources to lose weight was substantial for some females; $19 \%$ reported that mothers, 15\% that sisters, and 13\% that brothers frequently or almost always encouraged them to lose weight. Pressure to gain weight was perceived to be substantial for some males; $16.7 \%$ reported that male friends and $11.5 \%$ that fathers frequently or almost always encouraged them to gain weight. Thus nutrition educators should consider these potential influences when working with either females or males. 


\section{ACKNOWLEDGEMENTS}

I would like to thank all of the faculty, students and friends who assisted with this study. I am very thankful to the faculty members of both the Home Economics department and in computer services who provided me with the assistance necessary to complete this project. Also, the friends that I have made here at EIU have been very supportive throughout the school term and I wish to thank them as well.

I sincerely want to thank Dr. Carol Ries for her encouragement to complete a masters thesis. Her encouragement and enormous time and effort enabled me to complete this study and may not have been possible without her. I would also like to thank my committee members, Dr. Martha Brown and Dr. Frances Murphy who also spent a great amount of time reviewing the project and providing valuable suggestions. Lastly, I would like to thank Dr. Dodd of testing services who provided a great deal of time with the data analyses. 


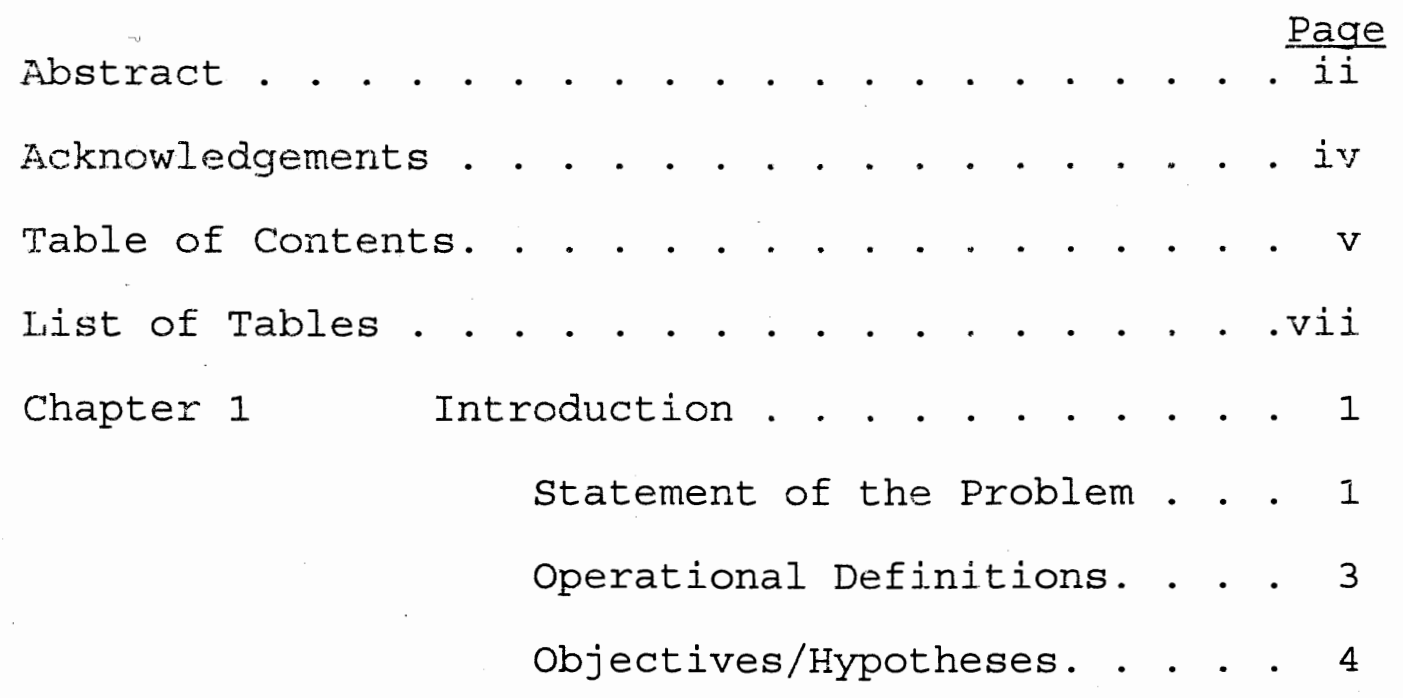

Chapter 2 Review of Literature . . . . . . 7

Body Image Perception. . . . . 7

Nature and Prevalence of Body Dissatisfaction Among Females and Males of Varying Ages. . . 7

Comparison of Distortion Among Different Weight Classifications. • . . . . 8

Body Image Satisfaction. . . 10

Prevalence of Body Satisfaction and Dissatisfaction Among

Females and Males. . . . . . 11

Societal Influences on

Perception and Satisfaction. . 16

Chapter 3 Methodology . . . . . . . . 21

Data Collection Instruments. . 21

Data Collection Methods. . . 23

Data Analyses. . . . . . 23.

Chapter 4 Results and Discussion. . . . . 25

Accuracy of Body Size

Perception . . . . . . . . 27

Body Shape Satisfaction. . . 30 
Perception of Body Shape

Considered Ideal by the

Opposite Sex . . . . . . 33

Perceived Influence of Significant Others on Body

Shape or Size. . . . . . . 34

Chapter 5

Summary, Conclusions and

Implications. . . . . . . . . . . . 43

Summary. . . . . . . . . . 43

Limitations. . . . . . . . 45

Conclusions . . . . . . . . 46

Implications . . . . . . . 47

References . . . . . . . . . . . . . . . . 48

Appendix A

Body Image Survey: Female. . 53

Appendix B

Body Image Survey: Male. . . 57 
Page

Table 1

Frequency Distribution of Self Reported Weight Classification by Gender and Actual weight

Classification. . . . . . . . . . 29

Table 2

Means and Frequency Distributions

of Figure Representations of

Current and Preferred Body Shape. . . . 32

Table 3 Mean and Frequency Distributions of

Figure Representations of Body

Shape Considered Ideal. . . . . . . 35

Table 4 Means and Frequency Distributions of

Perceived Influence of Significant

Others Encouraging Subjects to

Increase Body Size. . . . . . . . . . 38

Table 5 Means and Frequency Distributions of

Perceived Influence of Significant

Others Encouraging Subjects to

Decrease Body Size. . . . . . . . . 39

Table 6 Means and Frequency Distributions of

Figure Representations of Students'

Perception of How Significant

Others View Them . . . . . . . . . . 41

Table 7 Mean Figure Representations of Females Self Perception of Body Shape Compared to Their Perception of How Significant

Others View Them. . . . . . . . . . 42 


\section{Chapter I}

\section{IN'TRODUCTION}

Statement of the Problem

Distorted body image, dissatisfaction with body shape and size and various eating disorders are all reportedly common in the United States (Cooper, Taylor, Cooper, \& Fairburn, 1987; Fowler, 1989; Garner, Garfinkel, Schwartz, \& Thompson, 1980; Heilbrun, \& Friedberg, 1990; Kurtzman, Yager, Landsverk, Wiesmeier \& Bodurka, 1989; Mortenson, Goerr, \& Garner, 1993; Paxton, Wertheim, Gibbons, Szmulker, Hillier, \& Pertovich, 1991; Wooley, \& Wooley, 1986). Both females and males are pressured to be thin, but these pressures are generally considered to be greater for females than for males (Collins, 1991; Fallon \& Rozin, 1985; Franzoi \& Shields, 1984; Paxton et al., 1991; Welch, Nidiffer, Zager, \& Lyerla, 1992; Wright, 1989). Females seem especially pressured to obtain and maintain a thin figure even if they are within normal weight limits, or if a thin shape is an unrealistic, or unhealthy goal (Kishchuk, Gagnon, Belisle, \& Laurendeau, 1992). This pressure to be thin is believed to lead to unsafe and even unnecessary weight loss behaviors and to be a major contributing factor in the etiology of various eating disorders (Garner et al., 1980; Klemchuk, Hutchinson \& Frank, 1990). Society may contribute to females' preoccupation with body weight and desire to be thin in a number of ways. 
Garner et al, (1980) suggest that the body image considered ideal by females may be influenced by magazines such as Playboy and by the Miss America pageant. Feldman, Feldman and Goodman (1988) suggest that children are learning to value thinness through cultural influences such as story books, radio and television, as well as from their

caregivers and peers. Wooley and Wooley (1986) suggest that adolescent females are learning weight loss practices from their mothers. Preoccupation with body weight and shape and weight loss behaviors have been reported to occur in females as early as third grade (Maloney, McGuire, Daniels, \& Specker, 1989). A better understanding of these influences would be useful in the development of educational efforts to promote healthful body weights and dietary practices for various audiences.

$$
\text { College-aged females (18 - } 24 \text { years) may be a }
$$
particularly important target audience to examine because of the prevalence of eating disorders that has been reported for this population (Klemchuk et al., 1990; Kurtzman et al., 1989; Wooley, \& Wooley, 1986). Kurtzman et al., (1989) found that the prevalence of eating disorders among college students may be as high as $14 \%$. Most females have completed puberty and have reached full adult size by this age. Presumably, both females and males by this age have been exposed to considerable societal influences that have shaped their perceptions of the body shape and size that is most 
valued. Many females and males at this stage of life are going through the process of mate selection, yet there is little in the literature about the influence of this factor on body shape perception and satisfaction.

The overall purposes of this study, therefore, were to examine how college-aged females and males think and feel about body shape and who influences their perceptions. Both females and males were studied in order to examine potential differences that might help explain the greater preoccupation with body weight and shape observed in females. The results of this study will be useful for nutrition educators who counsel females and males on healthful diets and realistic body weight and shape.

\section{Operational Definitions}

The following terms have been operationally defined for the study:

Body shape/image: the figure or form of the body in relation to actual height and weight.

Perceived body shape/image: the mental picture an individual has about her/his own or other persons' body shape.

Ideal or preferred body shape: body shape which the individual considers most attractive or most desirable. Ideal or preferred body weight: body weight which the individual desires to weigh.

Body Mass Index (BMI): Calculation based on actual body weight and height. Weight in kilograms divided by 
height in meters squared. For this study, subjects were classified as underweight, normal weight or obese using the following cut off points as described by Thomas (1993).

Males: Underweight $=$ BMI less than or equal to 20.7

Normal weight $=$ BMI greater than 20.7 and less than 27.8 .

Overweight $=$ BMI greater than or equal to 27.8 .

Females: Underweight $=$ BMI less than or equal to 19.1 .

Normal weight $=$ BMI greater than 19.1 and less than 27.3 .

Overweight $=$ BMI greater than or equal to 27.3

Significant other: a person who is of great importance to the subject including mothers, fathers, brothers, sisters, boy/girlfriends, male friends and female friends.

Objectives/Hypotheses

The specific objectives and related hypotheses of this study are as follows:

1. To determine whether college students perceive their body shape accurately.

*Males will perceive their body shape accurately. 
* Females will perceive their body shape accurately.

2. To compare perceived body shape with preferred body shape.

*Preferred body shape of males will be the

same as their perceived body shape.

* Preferred body shape of females will be the same as their perceived body shape.

3. To compare the female body shape that female college students believe males consider ideal to the female body shape male college students report as ideal.

*There will be no difference in the female body shape females believe males consider ideal and what males report as ideal for females.

4. To compare the male body shape that male college students believe females consider ideal to the male body shape female college students report as ideal.

*There will be no difference in the male body shape males believe females consider ideal and what females report as ideal for males.

5. To determine to what extent significant others encourage male and female college students to change their body shape by increasing or decreasing body size. 
6. To compare how male and female college students view themselves, in terms of body shape, with how they believe significant others view them. 


\section{Chapter II}

\section{REVIEW OF LITERATURE}

This literature review will examine research on body image perception, body image satisfaction, and various societal influences on both perception and satisfaction.

\section{Body Image Perception}

Body image perception has been defined as a mental picture of one's body. It is the product of conscious and unconscious perceptions, attitudes and feelings. Inherent in the concept are the values, beliefs, needs, experiences both past and present, and expectations of society (Fowler, 1989) .

Nature and Prevalence of Body Distortion Among Females and Males of Varying Ages

Many investigators have suggested that inaccurate or distorted body image perception is common, especially among females (Dolce, Thompson, Register, \& Spana, 1987; Fraenkel, Steiger, \& Leichner, 1989; Heilbrun, \& Friedberg, 1990; Kreitler \& Chemerinski, 1990; Wardle \& Foley, 1989). A substantial number of females perceive themselves to be overweight and want to be thinner (Collins, 1991; Desmond, Price, Gray \& O'Connell, 1986; Fallon \& Rozin, 1985; Greenfield, Quinlan, Harding, Glass, \& Bliss, 1987; Gustafson-Larson \& Terry, 1992; Maloney et al., 1989; Paxton et al., 1991; Welch et al., 1992; Wertheim, Paxton, Maude, Szmukler, Gibbons \& Hillier, 1992). Females have been found 
to be concerned with sexual attractiveness, body weight, and physical condition, whereas males have been found to be more concerned with physical attractiveness, upper body strength, and physical condition (Franzoi \& Shields, 1984). This suggests that males and females may be perceiving their body shapes differently.

Desmond et al. (1986) examined 194 high school students' actual and perceived weights. Based on National Health Survey data percentiles for sex and height, they classified the subjects as being thin (less than the 25 th percentile), normal, or heavy (greater than the 75th percentile). Of the 93 males and 191 females, 27\% were classified as being thin, $52 \%$ were normal, and $21 \%$ were heavy. Thirty percent of the adolescents perceived their weight classification inaccurately when compared to their actual weight and height. Fifty-seven percent of the males classified themselves as normal weight and $24 \%$ classified themselves as thin. Comparatively, $47 \%$ of the females classified themselves as heavy and 37\% classified themselves as thin. This suggests that more females are perceiving themselves to be heavier than they actually are compared to males.

\section{Comparison of Distortion Among Different Weight}

\section{Classifications}

Body image distortion may play a motivational role in continued dieting for females and may be a developmental 
factor in anorexia nervosa and bulimia (Heilbrun \& Friedberg, 1990; Fowler, 1989; Fraenkel et al., 1989 \& Welch et al., 1992). Females of different weight classifications have been found to perceive their body shapes differently. Kreitler and Chemerinski (1990) studied 74 obese and 66 non-obese women to determine body size distortions in relation to body image disturbance. Through the use of the Body Size Estimation Task and Human Figure Drawings, they found that the subjects overestimated the size of their waists and hips. The results of a study by Wardle and Foley (1989) were very similar. They used a moving light technique for body size estimation of 20 normal weight college females and concluded that the subjects accurately perceived their shoulder width, but overestimated their waist and hip size.

Heilbrun and Friedberg (1990) completed a study examining 100 college aged women. Using an unstructured 10inch scale labeled "very thin" at one end and "very fat" at the other, the women rated the size of their bodies after looking in a mirror. Actual body size was calculated by dividing the subjects' weight in pounds by their height in inches. The Body Perception Index (BPI) was then calculated as perceived body size divided by actual body size times 100. Using the Eating Disorder Inventory scale (EDI), the subjects were divided into two groups, anorexic personality and control group. Each of these groups were then 
subdivided into two sub groups (thinner and fatter)

according to actual body weight. The results indicated that the thinner subjects overestimated their body size more often than the fatter subjects and the anorexic personality subjects more often overestimated their body size than did control group subjects. This research suggests that distorted body images may be a sign of unhealthy body shape concerns and may be a factor in dieting behaviors in females.

Dolce, Thompson, Register, and Spana (1987) studied thirty-four normal weight college women for body size estimation. The researchers found that when the subjects were asked to estimate their own body size and the body size of a store mannequin, they overestimated their own body size but not that of the mannequin. These data suggest that body size distortion is not only caused by visual-spacial defects but also by cognitive/affective influences.

\section{Body Image Satisfaction}

A thin body shape has become the accepted and desired body image in society today (Casper \& Offer, 1990; Collins, 1991), although for many it may be a biologically unrealistic and often unhealthy goal (Kishchuk, Gagnon, Belisle, \& Laurendeau, 1992; Klemchuk, Hutchinson, \& Frank, 1990; Mortenson, Goerr, \& Garner, 1993). Obesity seems to have become socially unacceptable and undesirable resulting in a society that fears obesity. Presumably, individuals 
who do not perceive themselves as thin and want to be attractive, accepted and competent, may be dissatisfied with their body shape and strive to achieve and maintain a thin body shape.

The prevalence of eating disorders may be as high as $14 \%$ among college students. Kurtzman et al. (1992) found that of the college females surveyed, $14.6 \%$ practiced self induced vomiting, $13.8 \%$ reported excessive and deliberate weight loss practices, $14 \%$ over exercised without enjoyment of the exercise and $25.4 \%$ felt fat despite others perceiving them to not be overweight. The misperceptions of body size may cause thin females to be dissatisfied with their body shape when in fact they are within normal weight limits and do not need to decrease their body size.

Prevalence of Body Satisfaction and Dissatisfaction Among Females and Males

Research suggests that body image satisfaction and dissatisfaction is different between males and females. Most investigators have found females to be more dissatisfied with their body size than males (Fallon et al., 1985; Greenfield, Quinlan, Harding, Glass, \& Bliss, 1987; Gustafson-Larson \& Terry, 1992; Paxton et al., 1991; \& Welch et al., 1992). Body shape satisfaction and dissatisfaction occurs throughout the life span beginning in childhood, continuing through puberty, and adulthood (Collins, 1991; Franzoi \& Shields, 1984; Gustafson-Larson \& Terry, 1992 ; 
Klesges, Mizes \& Klesges, 1987).

The development of body image dissatisfaction among females has been reported to occur at a young age (Collins, 1991; Feldman et al., 1988; Gustafson-Larson \& Terry, 1992; Maloney et al., 1989). Children may be learning the values of beauty and thinness even before they have reached puberty. Maloney et al. (1989) reported that children age eight to 13 years in their study admitted having diet preoccupations. Approximately seven percent of the children were classified as having anorexia nervosa. Fifty-five percent of the girls and 35\% of the boys wished to be thinner. Forty-one percent of the girls and $31 \%$ of the boys had used some form of weight loss method to try and obtain a thin body shape. Common weight loss techniques included exercise (40.3\%) and restricting calories (12.6\%).

Similar weight related behaviors and body image dissatisfaction of children have been reported by GustafsonLarson and Terry (1992). More than $60 \%$ of the 457 fourth grade students they studied reported that they very often or sometimes wished they were thinner, worried about being fat and weighed themselves daily. About $40 \%$ said they had tried dieting. Significantly more of the girls (46.3\%) than of the boys $(23.6 \%)$ wished to be thinner. The authors concluded that preadolescents appear to have fixations with their body figure and a fear of obesity which is leading to diet preoccupations and weight loss practices. 
Collins (1991) used a pictorial instrument to examine body figure perceptions of 1118 preadolescent children. Body Mass Index was calculated to determine if males and females were under weight, of normal weight, or overweight. The subjects then chose the figure they believe represented their figure and the figure they would like to be. The results indicated that $42 \%$ of the females chose a figure they would like to be that was thinner than the figure they believed represented their present shape, whereas, only $30 \%$ of the males chose a figure thinner than their perceived current figure. The preference to be thinner increased with an increasing BMI for both males and females, but twentyfour percent of the females who had low BMI scores chose to be a thinner figure. This suggests that even females who are not overweight are desiring to be thinner. Overall, more males than females preferred to be heavier and more females preferred to be thinner. These findings are consistent with other research indicating that females more often than males have a desire to be thinner (Casper et al., 1990; Fallon et al., 1985; Felts et al., 1992; Franzoi \& Shields, 1984; Klesges et al., 1987; Maloney et al., 1989; Paxton et al., 1991; Wadden, Brown, Foster \& Linowitz, 1991; Wardle \& Foley, 1989; Wertheim et al., 1992; Wright, 1989). Fowler (1989) suggested that once children reach adolescence, the pubertal changes which include an increase in weight may increase the incidence of body shape 
dissatisfaction. She examined the relationship of body image perception to weight status among 90 female adolescents ranging in age from 13-17 years in order to determine if a recent change in weight status is correlated with body image perception. The Body Cathexis Scale used to determine body satisfaction includes 40 Likert-type questions on physical characteristics. The scale assesses the strength of respondents' feelings about each part or function of the body. The responses were classified as feelings of dislike, as neutral feelings or as positive feelings about these physical characteristics. The subjects also self-reported recent changes in weight status. The subjects were classified as being non-obese, overweight, or obese based on actual heights, weights and skinfold measurements. The results indicated that changes in weight which occur in puberty, do correlate with a negative body image of female adolescents.

Paxton et al. (1991) assessed body image satisfaction among 341 female and 221 male high school students. The investigators found that significantly more females than males were dissatisfied with their body shape. Forty-six percent of the girls and $18 \%$ of the boys believed they were overweight or very overweight. Using the Body Mass Index, subjects were classified as below the normal weight, of normal weight, above normal weight and very above normal weight. The researchers found $25.8 \%$ of the females and 
$27.6 \%$ of the males to be above or very above normal weight. Nearly two-thirds of these overweight adolescents, believed that being thinner would have a great impact on their lives. Females believed that being thinner would positively affect their lives, whereas, males believed that being thinner would have a negative impact on their lives.

Other studies have indicated that because of a desire to be thin, weight loss behaviors are prevalent. In a study completed by Wertheim et al. (1992), 606 female and 315 male adolescents were sampled. Seventy-one percent of the females and $34 \%$ of the males indicated they would like to have a smaller body shape. Weight loss behaviors reported by the adolescents associated with the desire to be thinner because the subjects perceived they would have greater psychosocial advantages if they became thinner.

Females have generally completed puberty by collegeage. It is therefore important to assess body image satisfaction among college age females. Kurtzman et al. (1989) surveyed 716 female UCLA students to determine body satisfaction and found the respondents desired to weigh an average of $13.4 \%$ less than the average weight suggested by the Metropolitan Life Tables. The authors indicated that when 348 men were surveyed, they desired on the average to weigh $1 \%$ more than the average weight suggested by the Metropolitan Life Tables. These findings support the argument that females are more concerned about having a thin 
body shape than are males. Kurtzman et al. (1989) concluded that these findings reflect how society emphasizes thinness for women.

At a university wellness center, of 106 college age students seeking nutrition counseling, $69 \%$ were women (Welch et al., 1992). Because more than half of the respondents were females, the authors suggested that more college women than men may be concerned with their body shape.

\section{Societal Influences on Perception and Satisfaction}

Body dissatisfaction occurs in both males and females but appears to be more prevalent among females of all ages. The fact that it is occurring is important to know, but it is also important to understand the etiology of body image distortions and dissatisfactions. Many factors such as the media and its' affects and how the family may influence body shape perceptions have been explored and may influence body shape satisfaction.

Society has developed an image of the ideal human body through television, movies and magazines. These sources are often suggesting that the ideal female should be thin (Feldman et al., 1988; Garner et al., 1980; Desmond et al., 1986). Fabian and Thompson (1989) suggest that teasing of children who are overweight may contribute to the desire to be thin. Thin females are often portrayed as being more attractive and successful. Thin body shapes are promoted 
through various products and mechanisms to achieve a thin body shape. The message seems to be clear that females must have a thin body shape to be accepted by society.

Garner et al. (1980) researched female body sizes portrayed in Playboy magazine and the Miss America Pageant in a 20 year period. They discovered that both the playboy centerfold models and the Miss America Pageant contestants have significantly decreased in body size over this time period. Weight, bust and hip measurements for these women have decreased in size each decade analyzed. Playboy models and Miss America Pageant contestants are often judged by males, therefore, the desire for females to be thin and be desired by men may be an influencial factor by this magazine and beauty contest. The researchers also reported a significant increase in the number of diet articles in magazines during the 20 year period. Between 1960 and 1969, the yearly mean of articles relating to diet was 17.1 ; between 1970 and 1978 the yearly mean was 29.6.

Wooley and Wooley (1986) suggest that parental behaviors and attitudes regarding obesity and weight loss may be factors influencing their daughter's perceptions of the desired body shape. The desire to be thin among adolescent females may stem from mother/daughter interactions. Mothers are often found to be concerned with their own weight and to use various methods to decrease their own body size. Adolescents, in particular females, are then learning their 
mothers' weight concerns and weight loss practices. Adolescents may also feel their mothers are critical of their own developing bodies and begin dieting to be accepted by their mothers.

Paxton et al. (1991) found that 19\% of the 341 females and $12 \%$ of the 221 male high school students sampled reported that their parents encouraged them to diet. Subjects whose parents encouraged them to diet reported dieting more frequently than did subjects whose parents did not encourage them to diet. Forty-six percent of the females and $52 \%$ of the males reported that at least one of their parents dieted; females who reported a dieting parent dieted more frequently themselves. Both females and males stated that their sources of information on diet and health were school, television, friends, magazines and parents. This study implies that parental interactions and beliefs regarding obesity may significantly influence adolescents' weight beliefs and behaviors leading to various weight loss practices and perhaps to increased incidence of distorted body images.

Not only are family pressures probable influences on females to maintain thin figures, but pressures from the opposite sex, including boyfriends, also may be a factor (Fallon \& Rozin, 1985; Wadden et al., 1991). Fallon and Rozin (1985) conducted a study to determine sex differences in perceptions of desirable body shape. A set of nine 
figure drawings ranging from very thin to very heavy were used by 248 male and 227 female subjects to indicate their current figure, ideal figure, the figure that they felt would be most attractive to the opposite sex, and the opposite sex figure to which they would be most attracted. When men compared their own current figure to the male figure females desired, the figures were almost identical. Females on the other hand, indicated that their current figures were heavier than the most attractive figure, which was also heavier than the ideal figure. Both men and women misperceived what body shape the opposite sex would find attractive. Men believed that womens' ideal male had a heavier build than what females reported they desire. Women believed that men desire a women who is thinner than what men actually reported they like. The authors conclude that female perceptions of what males desire places increased pressure on them to lose weight. Therefore, females may be at a greater risk for dieting and eating disorders.

The desire to maintain a thin body shape seems to be prevalent among females which is leading to a pursuit to be thin. Society, including the media, parents and peers, may be contributing to body shape perceptions and what body shape is desired. Due to the pressures to be thin and apparent body distortions, the incidence of body dissatisfaction among males and in particular females is prevalent. Further research of a college-aged population 
may be beneficial in the effort to educate males and females to decrease the incidence of body distortion, dissatisfaction and eating disorders. 


\section{Chapter III}

\section{METHODOLOGY}

This study was conducted to determine how college-aged females and males think and feel about body shape and who influences their perceptions. Both females and males were studied in order to examine potential differences that might help explain the greater preoccupation with body weight and shape observed in females.

\section{Data Collection Instruments}

Instruments used for the data collection included a questionnaire and Detecto-calibrated balance scale. The questionnaire (Appendix $A$ and $B$ ) included questions regarding demographics, body image, and a pictorial scale which indicated various body shapes. Demographic questions were developed to help describe the sample. These questions assessed each subject's age, year in school, major, place of residence, and whether the subject was currently dating anyone exclusively, and if so, for how long. The relevance of this information was to obtain a description of the sample. The last four digits of the social security number served as confidential identification.

Questions were also developed to determine current and ideal body size. Three multiple choice questions examined the subjects' perception of their weight. Nine questions, using a Likert-type scale of $4=$ almost always to $1=$ rarely, examined the degree to which subjects felt their 
mothers, fathers, siblings, boyfriends/girlfriends, female friends, male friends, and self encouraged them to gain weight. Nine similar questions examined the degree to which they felt these significant others and self encouraged them to lose weight.

A pictorial scale used by Rozin and Fallon (1985) was used to examine body shape perceptions. This scale includes numbered drawings of nine female and nine male body figures that range from being very thin to very obese. Subjects were asked to indicate which figure best represented their current body shape, the body shape they would like to be, the body shape they believe the opposite sex desires, the opposite sex body shape they consider ideal, and the body shape they believe is how each of several significant others (mother, father, brother, sister, boy/girlfriend, female friends, and male friends) view them.

Actual heights and weights of each subject were measured using a Detecto-calibrated balance scale. The same experimenter obtained the height and weight data from all subjects to maintain consistency in recording measurements.

Reliability of the questionnaire was determined by 16 volunteer students from a home economics food preparation class who participated in a pilot test. Volunteers completed the questionnaire during class time and actual heights and weights were measured. Three home economics faculty reviewed the questionnaire to determine content 
validity.

\section{Data Collection Methods}

The students from a general education nutrition course completed the questionnaire and were weighed and measured during the regularly scheduled class time. Students recorded some responses on the questionnaire and some on computer answer sheets. They received extra credit points for participating. For weighing and measuring, the scale was calibrated for accuracy and the subjects took off their shoes. For consistency in measuring the subjects, the same experimenter obtained all of the heights and weights. For confidentiality, height and weight were coded by the last four digits of students' social security number and recorded directly on the answer sheet.

\section{Data Analysis}

Body Mass Index (BMI) values for each student were calculated by the investigator using actual weights and heights and the standard BMI formula of weight $(\mathrm{kg})$ divided by height (m) squared (Thomas, 1993).

BMI values plus students' open-ended and other responses were recorded directly on the questionnaire and then transferred to the appropriate computer answer sheets which were then scanned by computer.

Male and female students were classified into weight groups based on their BMI values as follows: underweight females (BMI = less than or equal to 19.1), normal weight 
females (BMI = greater than 19.1 and less than 27.3) and overweight females (BMI= greater than or equal to 27.3), underweight males (BMI= less than or equal to 20.7), normal weight males (BMI= greater than 20.7 and less than 27.8), and overweight males (BMI = greater than or equal to 27.8 ). The cut-off points are as described by Thomas (1993) and were chosen because of the large normal weight range. This allows for a substantial number of subjects to be classified as normal weight and therefore does not promote excessive thinness.

All data were analyzed using the 1990 sPSS statistical program (Norusis, 1990). Frequency distributions and means were computed for the whole sample and for males and females separately. Chi-squared analyses were used to determine differences between male and female responses for continuous variables. Analyses of variance were used to determine differences in mean responses among underweight, normal and overweight subjects. 


\section{Chapter IV}

\section{RESULTS AND DISCUSSION}

The sample included 171 Eastern Illinois University students who completed the questionnaire and were weighed and measured for their actual height and weight. One hundred twenty five females and 46 males participated with ages ranging from 17 to 32 years; mean age was 19.2 years. Over half (59.4\%) of the total sample and roughly two-thirds $(66.9 \%)$ of the females and one-third (39.1\%) of the males were freshmen. The sample also consisted of $20.6 \%$ sophomores, $12.9 \%$ juniors, $6.5 \%$ seniors and $.8 \%$ graduate students. Students in the sample represented a variety of majors. The distribution of majors included $24 \%$ business, $22 \%$ undecided, $18 \%$ education, $12 \%$ home economics, $8 \%$ social science, $8 \%$ health studies, $4 \%$ general science, and $4 \%$ speech communication majors.

Although most $(77 \%)$ of the students indicated they live in the dormitories, $15.9 \%$ reported they live in apartments, $5.3 \%$ in sorority or fraternity houses, and $1.8 \%$ at home. This high percentage of residence hall students is not surprising since freshman are required to live in the dormitories.

Height, weight, and BMI varied widely among participants. Height ranged from 53 inches to 75 inches with a mean height of 66.4 inches. Female height ranged from 53 inches to 73 inches with a mean of 64.90 inches. 
Male height ranged from 66 inches to 75 inches with a mean of 70.43 inches. The range of actual weight in females was 102 to 309 pounds; mean weight was 144.7 pounds. For males the range was 108 to 264 pounds; mean weight for males was 175.5 pounds. The mean BMI for females was 24.1 with a range of 17.1 to 50.2. The mean BMI of the males was 24.7 with a range of 16.9 to 33.1 .

The subjects were asked to what extent they were concerned about their body shape. Nearly $60 \%$ of the females and $39 \%$ of the males stated they were very concerned about their body shape. Only .8\% of females and $6.5 \%$ of males indicated they were not at all concerned. These results are consistent with previous research indicating that females are more concerned about their body shape (especialíy being thinner) than are males (Fallon \& Rozin, 1986; Greenfield et al., 1987; Gustafson-Larson \& Terry, 1992). "GustafsonLarson and Terry (1992) reported that $46.3 \%$ of the girls surveyed wished to be thinner compared to $23.6 \%$ of the boys. Collins (1991) used a questionnaire containing figure representations. The results indicated that $42 \%$ of females chose a figure they would like to be that was thinner than the figure they believed represented their present shape, whereas, only $30 \%$ of the males chose a figure thinner than their perceived current figure.

When the subjects in the present study were asked how old they were when they first started worrying about their 
body shape, about half (51\% of the total sample; $48.8 \%$ of females; $56.5 \%$ of males) indicated their concern began in high school, but $17 \%$ of the total sample (12.2\% of females; $4.2 \%$ of males) indicated that body shape preoccupations began as early as elementary school. This suggests that education regarding appropriate body weight may need to begin in elementary school.

\section{Accuracy of Body Size Perception}

Objective 1 . To determine whether college students perceive their body size accurately.

Related Hypotheses:

*Males will perceive their body size accurately.

*Females will perceive their body size accurately.

Based on individual body mass index (BMI), subjects were classified as being underweight, normal weight or obese (Thomas, 1993). Ninety-five females (77\%) and 28 males $(60 \%)$ were classed as normal weight, eight females $(6 \%)$ and nine males (20\%) were classed as underweight, and 21 females $(17 \%)$ and nine males $(20 \%)$ were classed as obese. Subjects were also classified as being underweight, normal weight or overweight based on their responses to the question, "Based on your weight, how would you classify yourself?" subjects were classified as underweight or overweight regardless of the specific underweight or overweight response they 
selected (i.e. less than 10 pounds, 11-20 pounds, or more than 20 pounds). Frequency distributions of these selfreported weight classifications by gender and by actual weight for the total group and for males and females separately are presented in Table 1.

Proportionally more males ( $30.4 \%$ ) than females ( $8.9 \%$ ) considered themselves underweight whereas more females $(62.9 \%)$ than males $(41.3 \%)$ considered themselves to be overweight (Table 1). This is consistent with previous findings indicating that females are more likely than males to consider themselves to be overweight (Collins, 1991; Desmond et al., 1986; Fallon \& Rozin, 1985; Paxton et al., 1991).

Both females and males who actually were obese or were underweight appeared to classify themselves accurately. Normal weight females and males appeared less likely to classify themselves accurately, but these results should be interpreted with caution since out of seven possible responses presented to students, only one of those represented normal weight. Also, the large proportion of normal weight individuals who classed themselves as overweight was likely due, at least in part, to the comparatively high BMI cut-off point $(27.8$ female and 27.3 males) used which restricted the upper actual weight group to those individuals who were obese. Thus, these data are not sufficient to reject either hypothesis. 
Table 1

Frequency Distribution of Self-Reported

Weight Classification by Gender and Actual weight Classification ${ }^{1}$

\begin{tabular}{|c|c|c|c|c|c|}
\hline$\sigma$ & & $\begin{array}{l}\quad \text { Sel } \\
\text { Under } \\
\text { Weight } \\
\text { (UW) }\end{array}$ & $\begin{array}{l}\text { Eion } \\
\text { Normal } \\
\text { Weight } \\
\text { (NW) }\end{array}$ & $\begin{array}{l}\text { Over } \\
\text { Weight } \\
\text { (0) }\end{array}$ & Significance ${ }^{2}$ \\
\hline Gender & $\begin{array}{l}\mathrm{M} \\
\mathrm{F}\end{array}$ & $\begin{array}{c}N=17 \\
30.4 \% \\
8.9\end{array}$ & $\begin{array}{c}N=124 \\
28.3 \% \\
28.2\end{array}$ & $\begin{array}{l}N=30 \\
41.3 \% \\
62.9\end{array}$ & .0013 \\
\hline \multicolumn{6}{|c|}{ Actual Weight ${ }^{3}$} \\
\hline $\begin{array}{l}\text { Total } \\
\text { Group }\end{array}$ & $\begin{array}{l}\text { UW } \\
\text { NW } \\
\text { Obese }\end{array}$ & $\begin{array}{r}82.4 \\
9.0 \\
---\end{array}$ & $\begin{array}{r}17.6 \\
35.2 \\
6.5\end{array}$ & $\begin{array}{l}--- \\
55.7 \\
93.5\end{array}$ & .0000 \\
\hline Male & $\begin{array}{l}\text { UW } \\
\text { NW } \\
\text { Obese }\end{array}$ & $\begin{array}{r}88.9 \\
21.4 \\
---\end{array}$ & $\begin{array}{l}11.1 \\
39.3 \\
11.1\end{array}$ & $\begin{array}{l}--- \\
39.3 \\
88.9\end{array}$ & .0000 \\
\hline Females & $\begin{array}{l}\text { UW } \\
\text { NW } \\
\text { Obese }\end{array}$ & $\begin{array}{r}75.0 \\
5.3 \\
---\end{array}$ & $\begin{array}{c}25.0 \\
34.0 \\
4.5\end{array}$ & $\begin{array}{l}60.6 \\
95.5\end{array}$ & .0000 \\
\hline
\end{tabular}

1 Based on responses to question, "Based on your weight, how would you classify yourself?".

2 Determined by Chi-square analyses.

3 Based on body mass index (BMI) according to Thomas (1993). 
Desmond et al. (1986) examined high school students' actual and perceived weights and found that $27 \%$ of the subjects were classified as being thin, 53\% were normal and 21\% were heavy. Thirty percent of the adolescents perceived their weight classification inaccurately when compared to their actual weight and height. Fifty-seven percent of the males classified themselves as normal weight and $24 \%$ classified themselves as thin. In comparison, $47 \%$ of the females classified themselves as heavy and 37\% classified themselves as thin. The results of the Desmond et al. (1986) study are somewhat inconsistent with the results of the present study. This may be due to this study's high BMI cut-off and to the fact that Desmond et al. (1986) used National Health Survey data percentiles for sex and height to classify subjects.

\section{Body Shape Satisfaction}

Objective 2: To compare perceived body shape with preferred body shape.

Related Hypotheses:

*Preferred body shape of males will be the same as their perceived body shape.

*Preferred body shape of females will be the same as their perceived body shape.

In order to estimate body shape satisfaction, subjects were asked to select the body figure which they felt best represented their current body shape and also the figure 
that represented the shape they preferred to be. The results (Table 2) indicate that the mean figure females preferred to be was roughly one figure smaller than what they perceived to be their current figure. The second hypotheses is therefore rejected. There was no significant difference in the males preferred shape and current shape. These data fail to reject the first hypothesis.

These results of females desiring to be smaller are consistent with previous literature. Maloney et al. (1989) found that $41 \%$ of the girls and $31 \%$ of the boys wished to be thinner. Collins (1991) discovered that $42 \%$ of the females studied chose a figure they would like to be that was thinner than the figure they believed represented their present shape, whereas, only $30 \%$ of males chose a figure thinner than their perceived current figure. Paxton et al. (1991) found that $46 \%$ of the girls and $18 \%$ of the boys surveyed believed they were overweight or very overweight. Results of male and female body shape satisfaction reported by Kurtzman et al. (1989) also are consistent. They found that females desired to weigh an average of $13.4 \%$ less than the weight suggested by the Metropolitan Life Tables and that males desired to be $1 \%$ heavier than the suggested weights. 
Table 2

Means and Frequency Distributions of Figure Representations ${ }^{2}$ of Current and Preferred Body Shape

\begin{tabular}{|c|c|c|c|c|c|c|c|c|c|}
\hline \multicolumn{10}{|c|}{ FIGURES } \\
\hline & 1 & 2 & 3 & 4 & 5 & 6 & 7 & Mean & \pm SD \\
\hline $\begin{array}{l}\text { FEMALES } \\
\text { Current } \\
\text { Shape }\end{array}$ & --8 & 8.18 & 21.88 & 45.28 & 20.28 & $2.4 \%$ & 1.68 & 3.95 & $1.05 * *$ \\
\hline $\begin{array}{l}\text { Preferred } \\
\text { Shape }\end{array}$ & 5.7 & 28.5 & 45.5 & 17.9 & 2.4 & $\cdots$ & $\cdots$ & 2.83 & $B 8 * * *$ \\
\hline $\begin{array}{l}\text { MALLES } \\
\text { Current } \\
\text { Shape }\end{array}$ & -.. & 4.3 & 30.4 & 19.6 & 30.4 & 13.0 & 2.2 & 4.24 & 1.21 \\
\hline $\begin{array}{l}\text { Preferred } \\
\text { Shape }\end{array}$ & -.. & 2.2 & 6.5 & 32.6 & 58.7 & $\ldots$ & ... & 4.48 & .72 \\
\hline
\end{tabular}

1. Figure drawings of each sex ranging ordinally from $1=$ very thin to 9 = very heavy; none of the students selected figures 8 or 9 .

***Preferred shape and current shape significantly different, $\mathrm{p} \leq .01$

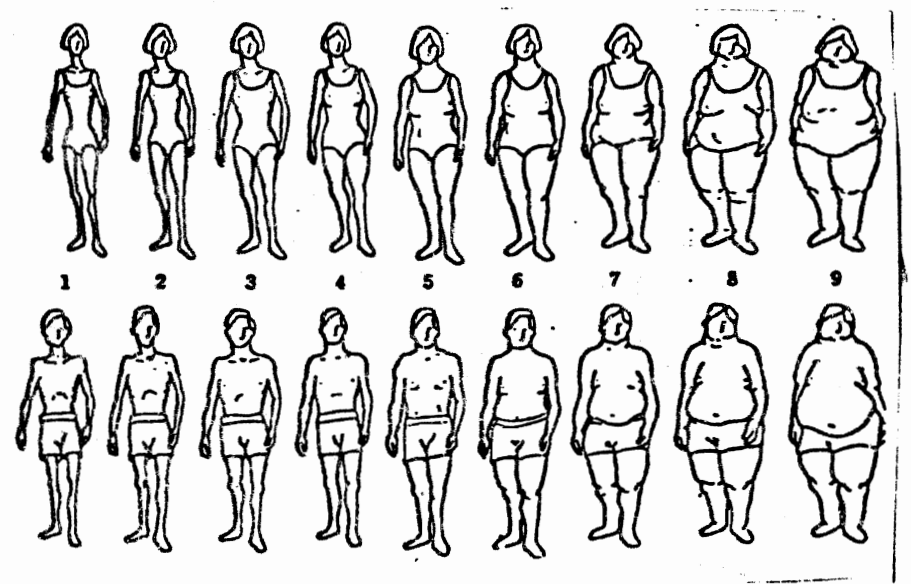

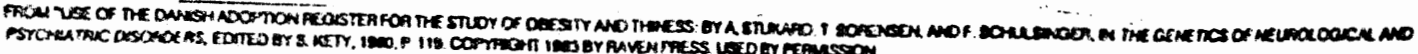




\section{Perception of Body Shape Considered Ideal \\ By the Opposite Sex}

Objective 3: To compare the female body shape that female college students believe males consider ideal to the female body shape male college students report as ideal.

Related Hypotheses:
*There will be no difference in the female body shape females believe males consider ideal and what males report as ideal for females.

Objective 4: To compare the male body shape that male college students believe females consider ideal to the male body shape female college students report as ideal.

Related Hypotheses:

*There will be no difference in the male body shape males believe females consider ideal and what females report as ideal for males.

Using a pictorial scale with nine figures ranging from very thin to very obese, the subjects were asked to select the same sex body shape they believe the opposite sex considers ideal and the opposite sex body shape they believed to be ideal. Results (Table 3) indicate a difference between the female body shape believed to be the male ideal and the female body shape males reported as ideal. Females seemed to feel that males prefer a thinner 
Eemale than males actually report. These data reject the hypothesis stating there will be no difference in the female body shape females believe males consider ideal and what males report as ideal for females.

Thexe was no significant difference, however, between the male body shape believed to be the female ideal and the male body shape females report as ideal. Therefore, these data fail to reject the hypothesis stating that there will be no difference in the male body shape males believe females consider ideal and what females reported as ideal for males.

1 These results are partially consistent with those of Fallon and Rozin (1985) who used the same pictorial scale to determine sex differences in perceptions of desirable body shape. They found that both men and women misperceived what body shape the opposite sex would find attractive. Men believed that womens' ideal male had a heavier build than what females reported they desire. Women believed that men desire a women who is thinner than what men actually reported they prefer.

\section{Perceived Influence of Significant others on Body}

\section{Shape or Size}

Objective 5: To determine to what extent significant others encourage male and female college students to change their body shape by increasing or decreasing body size. Nine questions were asked to determine the influence 
Table 3

Mean and Frequency Distributions of Figure Representations ${ }^{1}$ of Body Shape Considered Ideal

FIGURES

1

2

3

4

56

Mean \pm SD Significance ${ }^{2}$

Female body

shape believed

to be male

ideal

$(\mathrm{N}=124)^{3}$

$1.7 \%$

$39.7 \% \quad 48.8 \%$

$8.3 \%$

$1.7 \%$

$--$

$2.69 \pm 1.05$

.000

Female body

shape males

believe is

ideal

$(\mathrm{N}=47)^{4}$

$\begin{array}{lll}4.4 & 62.2 & 26.7\end{array}$

6.7

$\pm .88$

Male body

shape believed

to be female

$2.2 \quad 37.0 \quad 58.7 \quad--\quad--4.52 \quad+1.21$

.011

Male body

shape females

believe is

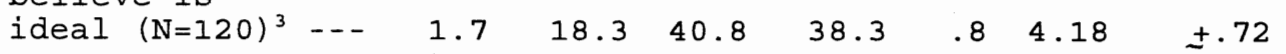

1.Figure drawings of each sex ranging ordinally from 1 = very

thin to 9 = very heavy; none of the students selected figures

$7-9$.

'Determined by Students' t-tests

3.Responses from females.

4.Responses from males. 
that students perceive various significant others have on encouraging them to change their body shape by increasing body size. Collectively, the results (Table 4) suggest that males feel they are encouraged to increase their body size somewhat more so than females, although mean degree of perceived influence from all sources was low for both females and males. There was a significant difference between males and females with regard to the perceived influence of "male friends" and "yourself" on increasing body size. Males were more likely to report these as sources of encouragement to gain weight than were females. Nine additional questions were asked to determine the influence that students perceive these significant others have on encouraging them to change their body shape by decreasing body size. Collectively, these results (Table 5) suggest that females feel they are encouraged to decrease their body size more so than males. Although mean degree of perceived influence from most sources was low, the response of "yourself" encouraging subjects to decrease body size was significantly higher for females than for males.

Although the mean degree of influence subjects perceived tha"t significant others place on them to increase or decrease size seems to be minimal, it is important to note that some subjects did report that significant others are encouraging them "frequently" or "almost always" to increase or decrease in size. Ten percent of the females 
responded that their mother "almost always" encourages them to decrease body size; an additional 9\% reported their mothers frequently encourage them. Fourteen percent of the females reported that their sisters "almost always" (3.3\%) or "frequently" (11.7\%) encourage them to decrease body size. Conversely, one male reported his mother "frequently" or "almost always" encourages him to decrease body size, and few reported this degree of influence from any other significant other. The fact that females seem to be pressured to be thin is consistent with previous literature. (Garner et al., 1980; Collins, 1991; Fallon \& Rozin, 1985; Franzoi, 1984; Paxton et al., 1991; Welch et al., 1992; Wright, 1989).

Garner et al. (1980) researched the influence that Playboy magazine and the Miss America Pageant may have on females desire to be thin. They found that both playboy centerfold models and Miss America contestants have had a significant decrease in body size over a 20 -year period. However data discovered by Paxton et al. (1991) is somewhat inconsistent with present study findings. They reported that $19 \%$ of 341 female students and $12 \%$ of 221 male students reported that their parents encouraged them to "frequently" or "almost always" diet. Wooley and Wooley (1986) suggest that parental behaviors and attitudes regarding obesity and weight loss may be factors influencing their daughters' perceptions of the desired body shape. 
Table 4

Means and Frequency Distributions of Perceived Influence of Significant Others' Encouraging Subjects to Increase Body Size

\section{Extent of Influence ${ }^{1}$}

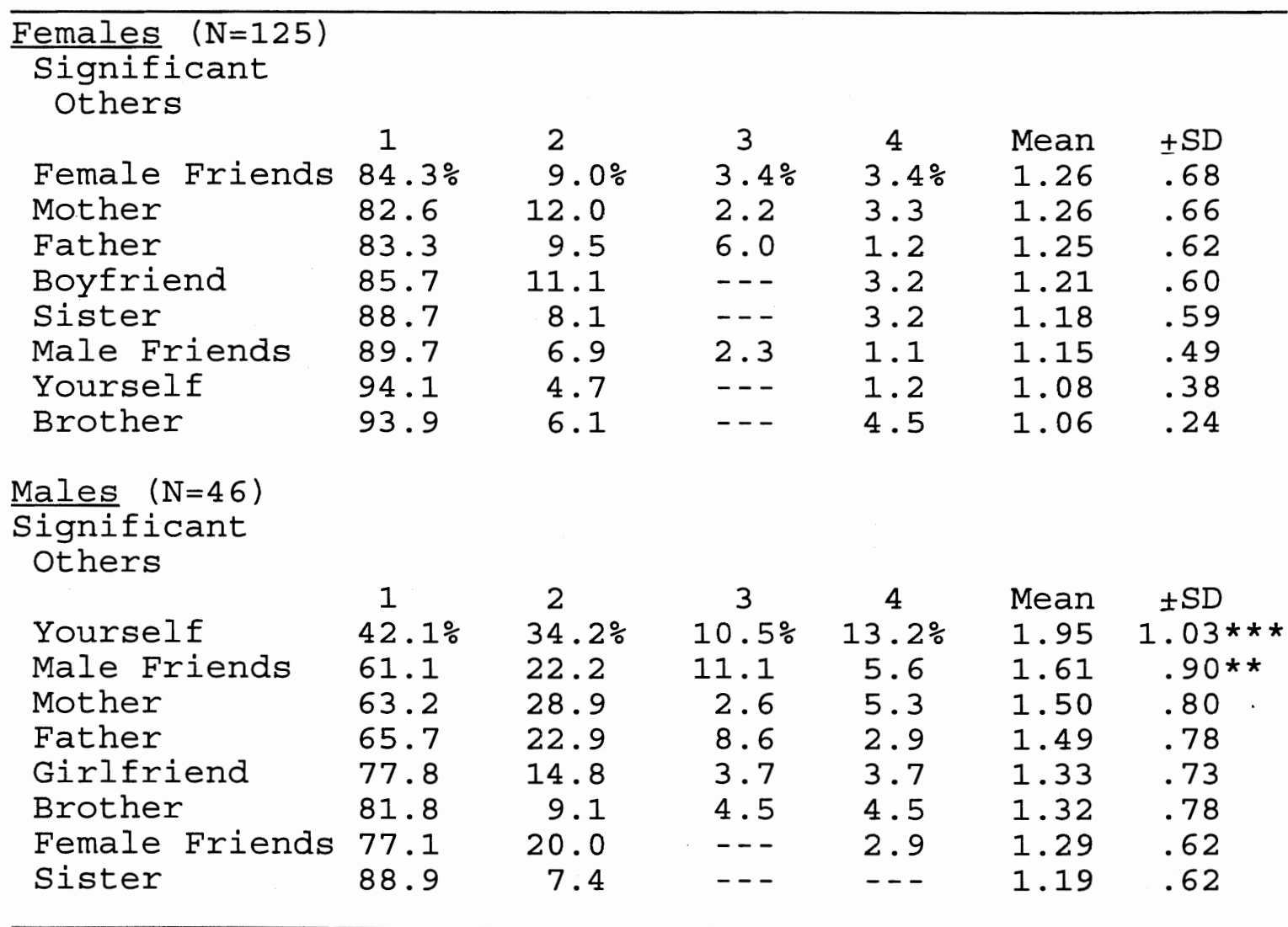

1.Responses to item, "Indicate the degree to which you feel they encourage you to change your body shape by increasing your body size". Response scale: $1=$ rarely, $2=$ occasionally, 3 = frequently, 4 = almost always encourage me to gain weight.

**Significantly higher than females, $p \leq .01$ ***Significantly higher than females, $\mathrm{p} \leq .0001$ 
Table 5

Means and Frequency Distribution of Perceived Influence of Significant Others Encouraging Subjects to Decrease Body Size

\section{Extent of Influence ${ }^{1}$}

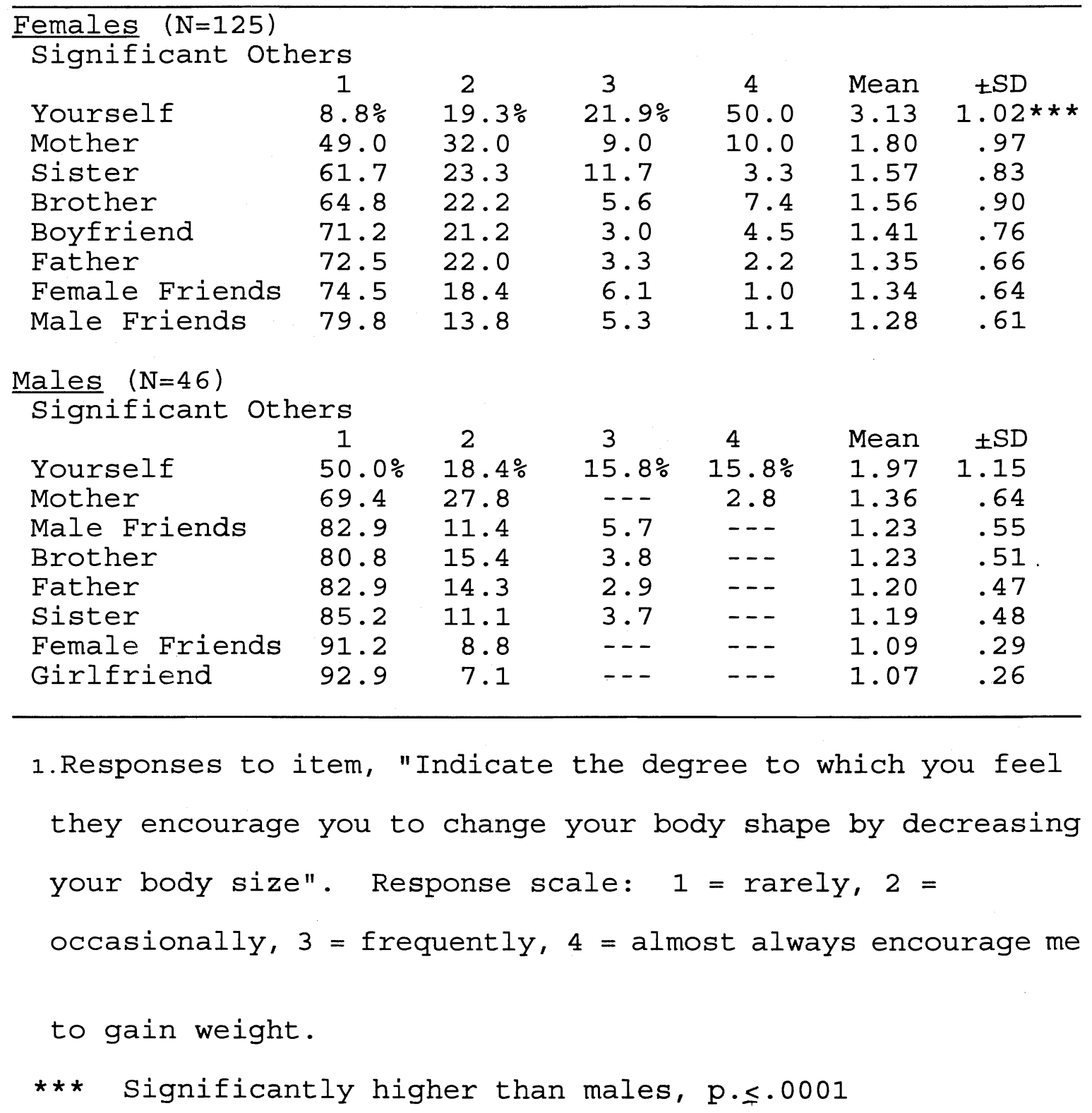


Objective 6: To compare how male and female college students view themselves, in terms of body shape, with how they believe significant others view them.

The subjects were asked to select the figure that they felt best represented their current body shape and the figures they felt best represented how significant others viewed them. Means and frequency distributions of figure representations of significant others view of their body shape are shown in Table 6. Students' t-tests were used to compare the subjects' self perception of body shape and their perceptions of significant others views (Table 7). Females reported their body size to be larger than how they believed several significant others viewed them. No previous literature has addressed subjects' self perception of body shape compared to their perceptions of how significant others view their body shape. This information is useful in educating individuals and significant others on healthful body shapes and sizes. 
Table 6

Means and Frequency Distributions of Figure Representations ${ }^{1}$ of Students' Perception of How Others View Them

\begin{tabular}{|c|c|c|c|c|c|c|c|c|c|c|}
\hline$\frac{\text { Females }}{\text { Female }}$ & 1 & 2 & 3 & 4 & 5 & 6 & 7 & 8 & Mean & $\pm S D$ \\
\hline Friends & $1.6 \%$ & $15.3 \%$ & $25.0 \%$ & $39.5 \%$ & $13.7 \%$ & $1.6 \%$ & $3.2 \%$ & $0.0 \%$ & 3.84 & 1.18 \\
\hline Brother & --- & 11.8 & 28.9 & 34.2 & 15.8 & 6.6 & 2.6 & --- & 3.83 & 1.19 \\
\hline $\begin{array}{l}\text { Mother } \\
\text { Male }\end{array}$ & 3.3 & 11.4 & 29.3 & 33.3 & 17.9 & 1.6 & 2.4 & -- & 3.70 & 1.25 \\
\hline Friends & --- & 10.7 & 26.2 & 42.6 & 14.8 & 3.3 & .8 & 1.6 & 3.69 & 1.13 \\
\hline Sister & 1.2 & 11.1 & 32.1 & 35.8 & 14.8 & 2.5 & 2.5 & -- & 3.66 & 1.13 \\
\hline Father & 2.6 & 14.5 & 28.2 & 36.8 & 12.0 & 4.3 & .9 & $\cdots$ & 3.62 & 1.24 \\
\hline Boyfriend & --- & 18.2 & 28.4 & 38.6 & 12.5 & 2.3 & --- & --- & 3.52 & 1.10 \\
\hline \multicolumn{11}{|l|}{ Males } \\
\hline Brother & --- & 13.3 & 10.0 & 20.0 & 43.3 & 6.7 & 6.7 & --- & 4.40 & 1.35 \\
\hline Girlfriend & $1--$ & 9.1 & 6.1 & 36.4 & 42.4 & 6.1 & $\cdots$ & --- & 4.30 & 1.02 \\
\hline $\begin{array}{l}\text { Sister } \\
\text { Male }\end{array}$ & --- & 8.8 & 23.5 & 11.8 & 47.1 & 5.9 & 2.9 & -- & 4.26 & 1.24 \\
\hline $\begin{array}{l}\text { Friends } \\
\text { Female }\end{array}$ & --- & 10.9 & 21.7 & 30.4 & 8.7 & 6.5 & --- & --- & 4.24 & 1.37 \\
\hline Friends & --- & 11.1 & 22.2 & 15.6 & 40.0 & 8.9 & 2.2 & --- & 4.20 & 1.27 \\
\hline Father & --- & 13.0 & 19.6 & 23.9 & 30.4 & 8.7 & 2.2 & --- & 4.20 & 1.45 \\
\hline Mother & --- & 8.9 & 24.4 & 24.4 & 31.1 & 11.1 & --- & -- & 4.11 & 1.17 \\
\hline
\end{tabular}

1.Figure drawings of each sex ranging ordinally from $1=$ very thin to 9 = very heavy; none of the students selected figure 9. 
Table 7

Mean Figure Representations ${ }^{2}$ of Females Self Perception of Body Shape Compared to Their Perception of How Significant Others View Them

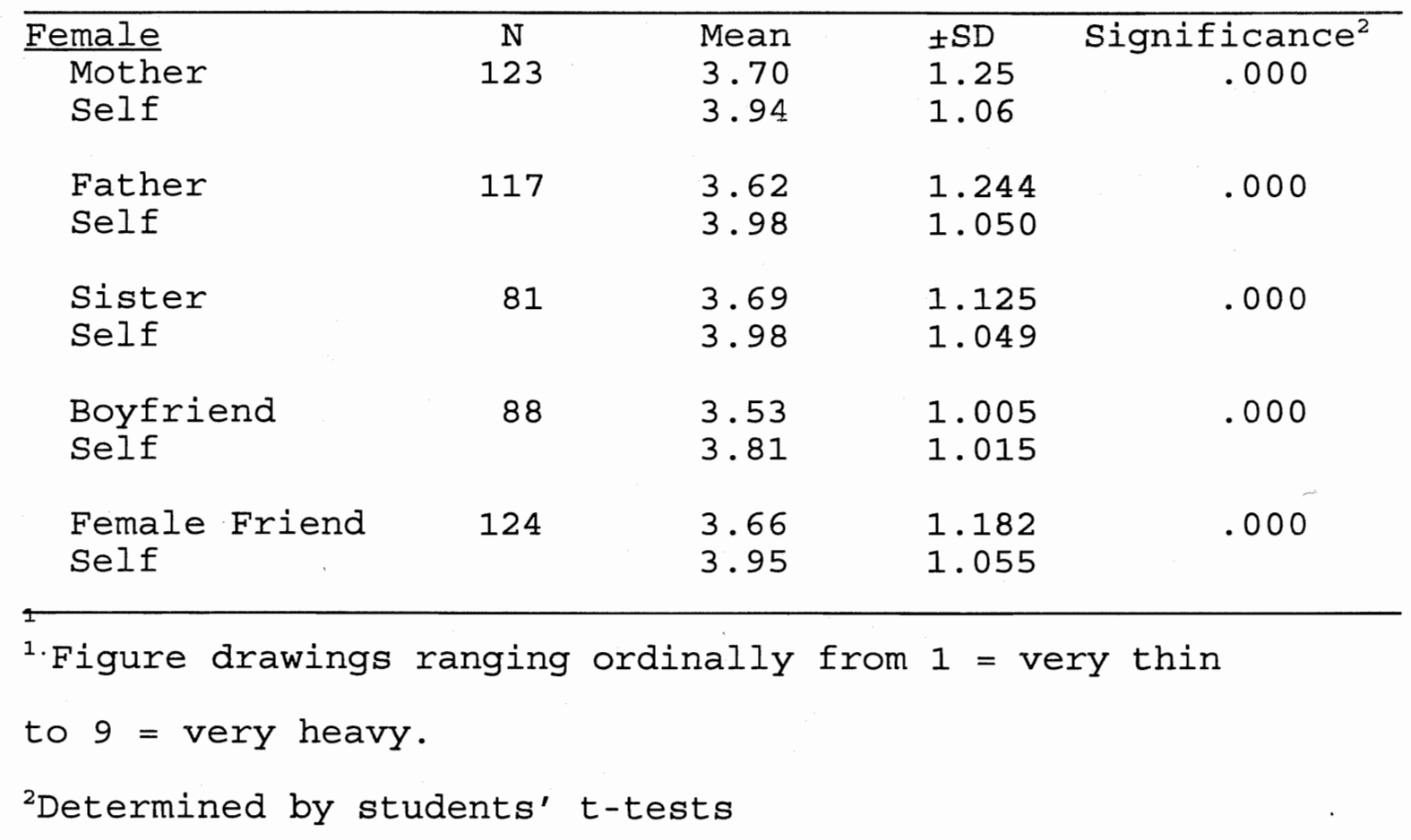




\section{Chapter V \\ SUMMARY, CONCLUSIONS AND IMPLICATIONS}

Summary

The purposes of this study were to examine how collegeaged females and males think and feel about body shape and who influences their perceptions. The results of this study will be useful for nutrition educators who counsel females and males on healthful diets and realistic body weights and shapes.

Data were collected from a sample of 171 college students enrolled in a general nutrition course at Eastern Illinois University, Charleston, Illinois. One-hundred and twenty five females and forty-six males completed a questionnaire and were weighed and measured for weight and height. The subjects' age ranged from 17-32 with a mean age of 19.2; in the sample a variety of majors were represented.

Using two sets of nine figure drawings (female and male) arranged from very thin $=1$ to very heavy=9, students indicated the figure they felt best represented (1) their current and (2) their preferred body shape, (3) the same sex shape considered ideal by the opposite sex, and (4) the opposite sex shape they considered ideal, and (5) how each of several significant others (mother, father, brother, sister, boy/girlfriend, male and female friends) viewed them. Students also indicated the extent to which they felt each of these significant others encouraged them ( $1=$ rarely 
to 4 =almost always) to change their body shape by gaining or losing weight.

Based on the Body Mass Index scale (BMI) classifications, $77 \%$ of the females and $60 \%$ of the males were normal weight, $6 \%$ of the females and $20 \%$ of the males were underwieght, and $17 \%$ of the females and $20 \%$ of the males were obese. Subjects self classification of weight compared to actual weight classifications indicated that $60.6 \%$ of the normal weight females classified themselves as overweight and $39.3 \%$ of the normal weight males classified themselves as overweight. Both females and males who were actually obese or underweight appeared to classify themselves accurately. Normal weight females and males appeared less likely to classify themselves accurately. Nearly $60 \%$ of the females and $39 \%$ of the males stated they were very concerned about their body shape. Only . 8\% of the females and $6.5 \%$ of the males indicated they were not at all concerned.

The results indicated that the mean preferred body shape of males(4.48) did not differ from the mean current shape (4.42), but the females' mean preferred shape (2.83) was thinner $(p<.01)$ than the mean current shape(3.95). Females believed that males prefer a thinner female(2.69) than males actually reported $(3.36, \mathrm{p}<.00)$; there was no difference in these means for males. Means of perceived influence from significant others (range=1.1-1.8) indicated that most males 
and females felt little pressure from these sources to gain or lose weight, especially in comparison to perceived selfinfluence of males to gain(2.0) and of females to lose(3.1) weight. Females perceived their body size to be somewhat larger (3.95, p<.000) than how they believed their mother or sister(3.7), male friends(3.66), father(3.62) or boyfriend(3.53) viewed them. Males' perception of their current shape was consistent with their perceptions of how others viewed them.

While mean influence scores suggest little perceived pressure from significant others to gain or lose weight for the sample as a whole, perceived pressure from these sources to lose weight was substantial for some females; $19 \%$ reported that mothers, $15 \%$ that sisters, and $13 \%$ that brothers frequently or almost always encouraged them to lose weight. Pressure to gain weight was perceived to be substantial for some males; $16.7 \%$ reported that male friends and $11.5 \%$ that fathers frequently or almost always encouraged them to gain weight.

\section{Limitations}

Several limitations of this study need to be addressed. The sample size of this study was small since only four nutrition classes were selected due to time constraints. The majority of the participants were females, therefore, the male sample may not be representative of college males in general. The fact that a general nutrition course was 
selected may bias the sample. Although the course meets the general education requirements, the students may be more concerned about nutrition and health than students who elect to take other courses. Other limitations regarding the questionnaire may include that fact that questions were not asked regarding ethnicity or race so it was not possible to examine potential differences among these different groups. The questionnaire also assumed respondents were heterosexuals; no questions were asked to identify sexual orientation.

\section{Conclusions}

Several conclusions about how college-aged females and males think and feel about body shape and who influences their perceptions can be drawn from this study:

1. Even many females who are classified as normal weight, desire a smaller body shape than their current shape.

2. Females believe that males prefer a thinner female body shape than what males report as ideal.

3. Consistent with previous research, females feel a greater pressure to attain and maintain a thin body shape compared to males who feel a greater pressure to attain and maintain a larger body shape.

4. Although most females perceive minimal pressure from significant others to lose weight, there 
are a substantial number of females who do report pressure from significant others.

Implications

Data from this study indicate that there is general dissatisfaction with body shape, predominantly among females but also among males. Previous research indicates that eating disorders are prevalent, therefore, counselors and dietitians should be aware of the potential influences significant others may have on individuals who are dissatisfied with their body shape. These data are valuable to counselors and dietitians for educational purposes when working with individuals of all ages to educate about healthful dieting practices and realistic body shapes and weights. 


\section{REFERENCES}

Casper, R. \& Offer, D. (1990). Weight and dieting concerns in adolescents, fashion or symptom? Pediatrics, 86, $384-390$.

Collins, M. (1991). Body figure perceptions and preferences among preadolescent children. International Journal of Eating Disorders, 10, 191-207. Cooper, P., Taylor, M., Cooper, Z., \& Fairburn, C. (1987). The development and validiation of the body shape questionnaire. International Journal of Eating Disorders, $\underline{6}, 485-494$.

' Desmond, S., Price, J., Gray, N., \& O'Connell, J. (1986). The etiology of adolescents' perceptions of their weight. Journal of Youth and Adolescence, 15, 461473 .

Dolce, J., Thompson, J., Register, A., \& Spana, R. (1987). Generalization of body size distortion. International Journal of Eating Disorders, ㅁ, 401-408.

Fabian, L. \& Thompson, J. (1989). Body image and eating disturbance in young females. International Journal of Eating Disorders, $8,63-74$.

Fallon, A., \& Rozin, P. (1985). Sex differences in perceptions of desirable body shape. Journal of Abnormal Psychology, 94, 102-105.

Feldman, W., Feldman, E., \& Goodman, J.T. (1988). Culture versus biology: Children's attitudes toward thinness 
and fatness. Pediatrics, 81, 190-194.

Fowler, B. (1989). The relationship of body image perception in weight status of the adolescent female. Adolescence, $\underline{24}, 557-566$.

Fraenkel, L., Steiger, H., \& Leichner, P. (1989).

Relationship of body image distortion to sex role identifications, irrational cognitions, and body weight in eating disordered females. Journal of Clinical Psychology, 4도 $61-65$.

Franzoi S., \& Shields S. (1984). The body esteem scale: Multidimensional structure and sex differences in a college population. Journal of Personality Assessment, $\underline{48}, 173-178$.

- Garner, D., Garfinkel P., Schwartz, D., \& Thompson, M.

(1980). Cultural expectation of thinness in women. Psychological Reports, 47, 483-491.

Gray, J., \& Ford, K. (1985). The incidence of bulimia in a college sample. International Journal of Eating Disorders, 4 , 201-208.

Greenfield, D., Quinlan, D., Harding, P., Glass, E. , \& BIiss, A. (1987). Eating behavior in an adolescent population. International Journal of Eating Disorders, 6 , 99-111.

Gustafson-Larson, A., \& Terry, R. (1992). Weight-related behaviors and concerns of fourth-grade children. Journal of the American Dietetics Association, 92, 818- 
822 .

Heilbrun, A., \& Friedberg, L. (1990). Distorted body image in normal college women: Possible implications for the development of anorexia nervosa. Journal of Clinical Psychology, 46, 398-401.

Kishchuk, N., Gagnon, G., Belisle, D., \& Laurendeau, M. (1992). Sociodemographic and psychological correlates of actual and desired weight insufficiency in the general population. International Journal of Eating Disorders, 12, 73-81.

Klemchuk, H., Hutchinson, C., \& Frank, R. (1990). Body dissatisfaction and eating-related problems on the college campus: Usefulness of the eating disorder inventory with a nonclinical population. Journal of Counseling Psychology, 37, 297-304.

Klesges, R., Mizes, J., \& Klesges, L. (1987). Self help dieting strategies in college males and females. International Journal of Eating Disorders, $\underline{6}, 409-417$. Koff, E., \& Keikhofer, M. (1978). Body part size estimation in children. Perceptual Motor Skills, 47 , 1047-1050.

Kreitler, S., \& Chemerinski A. (1990). Body-Image Disturbance in Obesity. International Journal of Eating Disorders, 9, 409-417.

Kurtzman, F., Yager, J., Landsverk, J., Wiesmeier, E. \& \& Bodurka, D. (1989). Eating disorders among selected 
female student populations at UCLA. Journal of the American Dietetic Association, 89, 45-50. Maloney, M., McGuire, J., Daniels, S., \& Specker, G. (1989). Dieting behavior and eating attitudes in children. Pediatrics, $\underline{3}, 482-487$.

Mortenson, F., Goerr, S., \& Garner, D. (1993). Predictors of body satisfaction in college women. Journal of the American Dietetic Association, 93, 1037-1039.

Norusis, J. (1990). Base System User's Guide. Chicago, Illinois: SPSS Inc.

Paxton, S., Wertheim, E., Gibbons, K., Szmulker, G., Hillier, L., \& Pertovich, J. (1991). Body image satisfaction, dieting beliefs, and weight loss behaviors in adolescent girls and boys. Journal of Youth and Adolescence, 20, 361-378.

Thomas, C. (1993). Tabor's Cyclogedic Medical Dictionary. Edition 17. Philadelphia: F.A. Davis Co. Wadden, T., Brown, G., Foster, G., \& Linowitz, J. (1991). Salience of weight related worries in adolescent males and females. International Journal of Eating Disorders, 10, 407-414.

Wardle, J., \& Foley, E. (1989). Body image: Stability and sensitivity of body satisfaction and body size estimation. International Journal of Eating Disorders, 8, 55-62.

Welch, T., Nidiffer, M., Zager. K., \& Lyerla, R. (1992). 
Attributes and perceived body image of students seeking nutrition counseling at a university wellness program. Journal of the American Dietetic Association, 92, 609611

Wertheim, E., Paxton, S., Maude, D., Szmukler, G., Gibbons, K., \& Hiller, L. (1992). Psychosocial predictors of weight loss behaviors and binge eating in adolescent girls and boys. International Journal of Eating Disorders, 12, 152-160.

Wooley, S., \& Wooley, W. (1986). Ambitious bulimics: Thinness mania. American Health, 10, 68-74. Wright, M. (1989). Body image satisfaction in adolescent girls and boys: A longitudinal study. Journal of Youth and Adolescence, 18, 71-83. 
Appendix A Body Image Survey: Female 
Body Image Survey

We are conducting a study to determine how college students think and feel about body shape and who influences their perceptions. This information will be useful in the development of nutrition education programs. Your responses will remain confidential. Thank you for contributing to the success of our project.

Susan Drake, Graduate Student

School of Home Economics

Dr. Martha Brown

Dr. Frances Murphy

A. Please provide responses for the questions on this page directly on this questionnaire.

1 . What are the last four digits of your social security number.

2. What is your age?

3. What is your major?

4. What is your height? ft in Weight? pounds

5. Are you dating anyone exclusively?

a. no

b. yes

How long have you been dating this person?

a. less than 6 months

b. 6 months to 1 year

c. more than 1 year to 2 years

d. more than 2 years to 4 years

e. more than 4 years

If you feel your boyfriend would be willing to participate in this study, please provide his full name and address (All names will remain confidential).

name

address 
B. For the following questions, please use a number 2 pencil and record your responses on the scan sheet. Please do not write on this portion of the questionnaire.

1. Where do you live?
a. in the dorms
b. in a sorority house
c. in an apartment or house off campus
d. at home with parents

2. What year in school are you?
a. freshman
b. sophomore
c. junior
d. senior
e. graduate student

3. Based on your weight, how would you classify yourself?
a. Underweight by more than 20 lbs
b. Underweight by 11-20 lbs
c. Underweight by less than 10 lbs
d. Normal or average weight
e. Overweight by less than 10 lbs
f. Overweight by 11-20 lbs
g. Overweight by more than 20 lbs

4. To what extent are you concerned about your body shape?
a. Not at all concerned
b. Sightly concerned
c. Very concerned

5. If you are concerned about your body shape, how old were you

when

you first started worrying about it?
a. elementary school (11 or younger)
b. junior high school (12-14)
c. high school (15-17)
d. college (18 and older)
e. never worried about my weight

Indicate, for each of the following persons in your life, the degree to which you feel they encourage you to change your body shape by INCREASING your body size.

6. Your mother

7. Your father 1 = rarely encourage me to gain weight

8. A brother

2 = occasionally encourage me to gain weight

9. A sister

3 = frequently encourage me to gain weight

4 = almost always encourage me to gain weight

10. Your boyfriend

11. Female friends

12. Male friends

13. Yourself

14. Other: please specify 
Indicate, for each of the following persons in your life, the degree to which you feel they encourage you to change your body shape by DECREASING your body size.

15. Your mother

16. Your father 1 = rarely encourage me to lose weight

17. Your brother 3 = occasionally encourage me to lose weight

18. Your sister, $10=$ not applicable

19. Your boyfriend

20. Female friends

21. Male friends

22. Yourself

23. Other: please specify

Indicate the number of the appropriate figure below for responses to items 24-34. Please mark 10 on your answer sheet if the item does not apply to you.
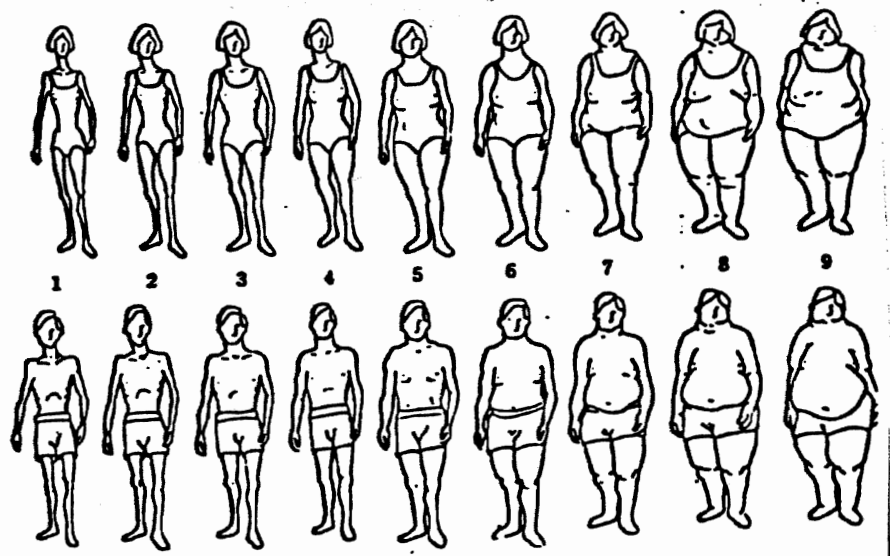

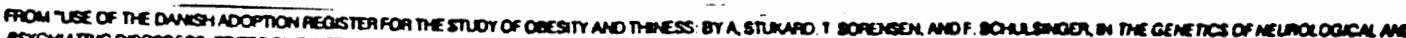

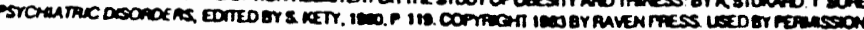

Which of the figures best represents:

24. How you believe your mother views you?

25. How you believe your father views you?

26. How you believe your brother(s) view you?

27. How you believe your sister(s) view you?

28. How you believe your boyfriend.. views you?

29. How you believe your male friends view you?

30. How you believe your female friends view you?

31. Your current body shape?

32. The body shape you would prefer to be?

33. The male body shape you consider to be ideal?

34. The female body shape you believe MALES consider to be ideal. 
Appendix B

Body Image Survey: Male 


\section{Body Image Survey}

We are conducting a study to determine how college students think and feel about body shape and who influences their perceptions. This information will be useful in the development of nutrition education programs. Your responses will remain confidential. Thank you for contributing to the success of our project.

\section{School of Home Economics}

Susan Drake, Graduate student

Dr. Carol Ries

Dr. Martha Brown

Dr. Frances Murphy

A. Please provide responses for the questions on this page directly on this questionnaire.

1. What are the last four digits of your social security number.

2. What is your age?

3. What is your major?

4. What is your height? ft in Weight? pounds

5. Are you dating anyone exclusively?

$$
\text { a. no }
$$

b. yes

How long have you been dating this person?
a. less than 6 months
b. 6 months to 1 year
c. more than 1 year to 2 years
d. more than 2 years to 4 years
e. more than 4 years

If you feel your girlfriend would be willing to participate in this study, please provide her full name and address (All names will remain confidential). name

address

B. For the following questions, please use a number 2 pencil and record your responses on the scan sheet. Please do not write on this portion of the questionnaire.

1. Where do you live?

a. in the dorms

b. in a fraternity house

c. in an apartment or house off campus

d. at home with parents 
2. What year in school are you?
a. freshman
b. sophomore
c. junior
d. senior
e. graduate student

3. Based on your weight, how would you classify yourself?
a. Underweight by more than 20 lbs
b. Underweight by 11-20 lbs
c. Underweight by less than 10 lbs
d. Normal or average weight
e. Overweight by less than 10 lbs
f. Overweight by 11-20 lbs
g. Overweight by more than 20 lbs

4. To what extent are you concerned about your body shape?
a. Not at all concerned
b. Sightly concerned
c. Very concerned

5. If you are concerned about your body shape, how old were you when you first started worrying about it?

a. elementary school (11 or younger)

b. junior high school (12-14)

c. high school (15-17)

d. college (18 and older)

e. never worried about my weight

Indicate, for each of the following persons in your life, the degree to which you feel they encourage you to change your body shape by INCREASING your body size.

6. Your mother

7. Your father

1 = rarely encourage me to gain weight

8. A brother

2 = occasionally encourage me to gain weight

3 = frequently encourage me to gain weight

9. A sister

4 = almost always encourage me to gain weight

10 = not applicable

10. Your girlfriend

11. Female friends

12. Male friends

13. Yourself

14. Other: please specify 
Indicate, for each of the following persons in your life, the degree to which you feel they encourage you to change your body shape by DECREASING your body size.

15. Your mother

16. Your father 1 = rarely encourage me to lose weight

2 = occasionally encourage me to lose weight

17. Your brother 3 = frequently encourage $\mathrm{mt}$ to lose weight

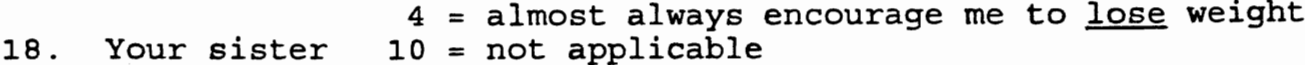

19. Your girlfriend

20. Female friends

21. Male friends

22. Yourself

23. Other: please specify

Indicate the number of the appropriate figure below for responses to items 24-34. Please mark 10 on your answer sheet if the item does not apply to you.

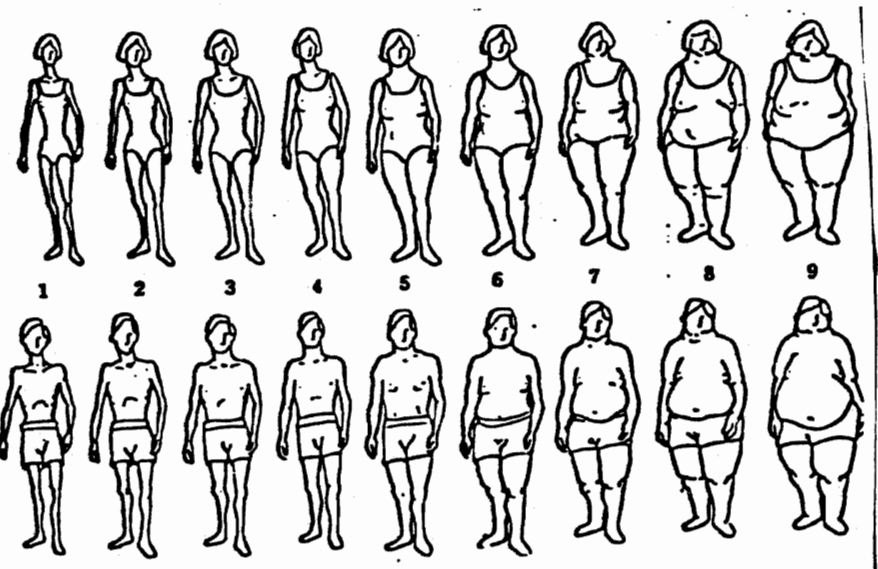

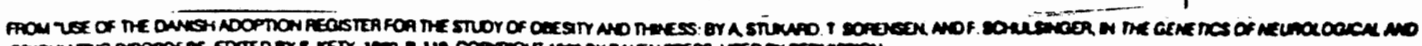

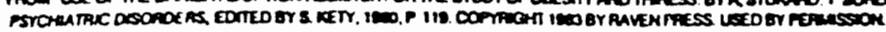

Which of the figures best represents:

24. How you believe your mother views you?

25. How you believe your father views you?

26. How you believe your brother(s) view you?

27. How you believe your sister(s) yiew you?

28. How you believe your girlfriend views you?

29. How you believe your male friends view you?

30. How you believe your female friends view you?

31. Your current body shape?

32. The body shape you would prefer to be?

33. The female body shape you consider to be ideal?

34. The male body shape you believe FEMALES consider to be ideal. 